\title{
En el bosque de la memoria: Identidad mapuche y escritura en dos obras de Elicura Chihuailaf
}

\author{
CARmen Gloria Godoy R. ${ }^{1}$
}

\begin{abstract}
RESUMEN
En este trabajo se intenta desarrollar una reflexión desde la antropología, respecto a la forma en que se articulan memoria, identidad étnica y escritura, a partir de la lectura de dos obras del poeta mapuche actual Elicura Chihuailaf. Más allá de tomar parte en la discusión que para algunos críticos y estudiosos de la literatura mapuche gira en torno al uso de la escritura en el contexto de una cultura basada en la tradición oral, o como rasgo manifiesto de aculturación o de una tendencia integracionista a la sociedad nacional, lo que aquí se propone es una aproximación al complejo proceso de configuración de un sujeto mapuche que constituye su identidad sobre los cimientos de una memoria individual y colectiva, haciéndolo desde el ejercicio de la escritura como experiencia de conocimiento de sí mismo y de su otro.
\end{abstract}

Palabras claves: memoria - identidad - sujeto - escritura.

\begin{abstract}
Two works of Elicura Chihuailaf (a contemporary Mapuche poet) provide the starting point for an anthropological reflection upon the way memory, ethnic identity and writing articulate each other. Rather than taking part in discussions by which some literary critics and researchers consider Mapuche writing to be an evident sign of acculturation in an orally based cultural tradition, towards integration with the national society, this paper is an approximation to the complex configuration process of a Mapuche subject, who constitutes its identity upon the foundations of individual and collective memory, using writing as a knowledge experience of itself and its-other.
\end{abstract}

Key words: memory - identity - subject - writing.

Recibido: octubre 2003. Manuscrito revisado aceptado: mayo 2004

\section{Marco de la reflexión}

El presente trabajo surge de dos inquietudes: una referida a los nuevos espacios y soportes utilizados en la actualidad para el posicionamiento de

1 Universidad Academia de Humanismo Cristiano. Dirección particular: Fitz Roy 1259, Las Condes, Santiago, CHILE. Email: cggodoy@vtr.net / cggodoy82@hotmail.com demandas y reivindicaciones de carácter étnico. Conocer cuáles son las estrategias y elementos utilizados, y cómo se va configurando o reconfigurando una identidad a partir de aquellas. Sobre todo, en relación al nuevo escenario que emerge desde la globalización para el desarrollo de procesos identitarios, en general, y de la emergencia de la denominada "cuestión étnica", en América Latina a partir de los años '90, particularmente en el caso del pueblo mapuche.

Dicha inquietud se vincula a las imágenes y representaciones sobre los "otros", es decir los indígenas, desde una sociedad mestiza que se funda como tal mucho menos en la inclusión que en la exclusión de aquellos. Esta exclusión es sostenida por un imaginario en el que los indígenas y su cultura en general tienden a ser vistos en un espacio y tiempo ajeno, ${ }^{2}$ distante, en el que la tradi-

2 Johannes Fabian realiza una crítica respecto a la forma en que su objeto de estudio, el otro, ha sido representado en el discurso antropológico. Fabian (1983) plantea que la antropología, como todo discurso científico, inevitablemente implica la temporalización, en cuanto a que el tiempo está envuelto en toda posible relación entre el discurso antropológico y sus referentes. Pero este referente no es ni un objeto, ni una clase de objetos, sino una relación entre culturas y sociedades, entre la sociedad occidental y los otros, las sociedades tradicionales. Estas serían vistas como en un espacio lejano al del antropólogo -occidental y moderno- y en un tiempo distinto al de su temporalidad, negando así la "convalidad", concepto con el que hace referencia al hecho de compartir una misma dimensión temporal. La persistente y sistemática tendencia de situar el/los referente/s de la antropología en un tiempo distinto al del presente del productor del discurso antropológico, la define como "alocronía". La visión de las poblaciones indígenas suele todavía estar asociada a una concepción alocrónica, como algo anclado en el pasado e incapaz de acceder a lo moderno por resistencia propia o por esa pobreza "endémica" que para algunos (fundamentalmente desde una perspectiva economicista) la caracterizaría. Lo que contribuye evidentemente a fomentar la imagen, en el caso de la sociedad chilena, de un sujeto que tuvo protagonismo en el momento de la invasión europea, de la "conquista española", pero que en cuanto dice adscribir a su identidad étnica y asumir su ascendencia indígena en la actualidad, o se 
ción aparece más como un obstáculo al desarrollo y al ingreso a la modernidad que como elemento constitutivo de una cultura. Desde esta perspectiva, la reivindicación de la memoria colectiva trae para algunos el eco de un discurso conservador, de una comunidad que se repliega sobre sí, sin dejar espacio a la comunicación y a la interacción con sus "otros".

La segunda inquietud relacionada con la anterior surge de la noción de "sujeto personal" planteada por Touraine (1997) a la luz de las fragmentaciones a las que somete una economía de carácter transnacional (la lógica instrumental) y las culturas (el orden de lo simbólico) a los individuos en el contexto de una nueva fase de la modernidad. Este "sujeto personal" sería una combinación de una "identidad personal y una cultura particular en un mundo racionalizado", afirmación de su libertad y su responsabilidad (Touraine 1997: 22).

Si bien la reflexión de Touraine emerge evidentemente de otro contexto social, me parece productiva en la medida que plantea una acción, una búsqueda emprendida por el propio individuo para generar las condiciones que le permitan ser actor de su propia historia; reivindicando su derecho a existencia individual pero sin desligarse del sentido que le otorga su comunidad de origen (Touraine 1997: 66).

El sujeto aquí no es una simple forma de la razón, lo moviliza tanto el cálculo y la técnica como la memoria y la solidaridad, "y sobre todo al combatir, indignarse, esperar, inscribir su libertad personal en las batallas sociales y las liberaciones culturales" (Touraine 1997: 67) que le permite establecer la comunicación de sujeto a sujeto.

\section{El autor}

Elicura Chihuailaf viene desarrollando una intensa producción escrita desde inicios de la década de los ' 80 , y se ha convertido en uno de los poetas mapuche más conocidos en Chile y en el extranjero (Figura 1). La poesía de Chihuailaf ha sido definida por críticos y especialistas en el tema como "poesía etnocultural", aquella en que el dis-

adapta a las exigencias de la "vida moderna" o se mantiene en la pobreza a costa de seguir siendo indígena. Impidiendo su comprensión y conocimiento en el plano de la coevalidad.

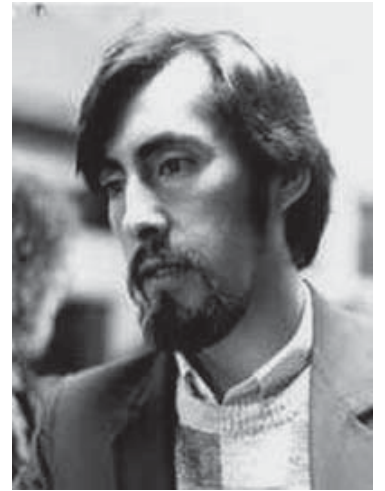

Figura 1. Elicura Chihuailaf.

curso poético se funda en la experiencia de la interacción de culturas indígenas, europeas y mestizas, siendo sus referentes la interculturalidad, el etnocentrismo, la marginalidad, la discriminación, el genocidio, enunciado por medio de la utilización de un lenguaje de codificación doble o plural, incluyendo estrategias textuales como el doble registro (en este caso mapudungun-español), la intertextualidad y el collage etnolingüístico, de acuerdo a lo planteado por Carrasco (1995: 58). ${ }^{3}$

Elicura Chihuailaf se propondría una escritura que se constituya como "el registro de la memoria histórica y étnica de la comunidad mapuche (...) 'a orillas de la oralidad aún vigente'.(...)”. Por ello, su proyecto de escritura quiere revitalizar, reconstruir o gestar un modo de ser genuinamente mapuche, porque piensa que la poesía como manifestación artística "no sólo resguarda los elementos de la identidad cultural de un pueblo, sino también los genera" (Chihuailaf, En el país de la memoria. cit. en Carrasco 2000).

Sin embargo, la escritura como forma de expresión "no alcanza a recoger la inmensidad de esa memoria que está pidiendo ser escrita" (Chihuailaf en Recado confidencial a los chilenos, p. 25).

\section{Los textos}

Los textos revisados fueron en su mayor parte Recado confidencial a los chilenos y De sueños

3 Carrasco agrega que el productor de este discurso poético se trata de un sujeto plural heterogéneo, poseedor de un saber etnocultural e histórico sincrético, que se presenta como un investigador, un sujeto participante étnico o históricamente implicado que se encuentra en el nivel de la enunciación y que denuncia o lamenta los hechos ocurridos. 
azules y contrasueños, a los cuales se suma la revisión de algunas entrevistas al autor. Es posible plantear como dificultad inicial el hecho de que Recado confidencial a los chilenos corresponde a un texto más bien de corte reflexivo, un ensayo -si lo entendemos desde los parámetros de la producción textual occidental-y al nvtram, una de las variadas expresiones de la tradición oral mapuche, el arte de la conversación, al cual hace referencia el propio autor. Mientras que De sueños azules y contrasueños (en el que se hace uso del doble registro lingüístico), sin embargo, correspondería más claramente a un texto poético, tanto en su dimensión estética como en su intencionalidad. No obstante, en ambos textos "habita el poeta" y se despliegan los elementos de un discurso particular, en cuanto a su lenguaje y a la centralidad del tema de la memoria como eje articulador de aquel; memoria que otorga sentido a la escritura, como producto final, como el texto escrito, pero también al acto de escribir y a la experiencia que ello involucra, en la configuración de una subjetividad que ya no puede estar condenada al silencio.

\section{Memoria, identidad y sujeto}

\section{Le Goff (1991: 131) define la memoria como:}

"la capacidad de conservar determinadas informaciones, [que] remite ante todo a un complejo de funciones psíquicas, con el auxilio de las cuales el hombre está en condiciones de actualizar impresiones o informaciones pasadas que él se imagina como pasadas".

Por otra parte, señala que:

"la memoria colectiva ha constituido un hito importante en la lucha por el poder conducida por las fuerzas sociales. Apoderarse de la memoria y del olvido es una de las máximas preocupaciones de las clases, de los grupos, de los individuos que han dominado y dominan las sociedades históricas. Los olvidos, los silencios de la historia son reveladores de estos mecanismos de manipulación de la memoria colectiva" (1991: 134).

Pero también entiendo memoria, en este contexto, como el ejercicio de actualización de un conjunto de valores, saberes y prácticas de carácter colectivo e individual. Desde esta perspectiva la memoria no es sólo lo restituido, sino aquella fuerza o motor que posibilita la configuración de un sujeto identitario mapuche y su discursividad, en un escenario inscrito y marcado por la asimetría en las relaciones, y por el tránsito del mundo reduccional al mundo urbano, de lo mapuche a lo chileno y de retorno al lugar de origen. En este sentido, la identidad, desde una perspectiva relacional, se entiende como un proceso de diferenciación respecto a otro, real o imaginario, así como se trata de una tensión entre permanecer y cambiar en el decurso del tiempo. Tensión en la que el otro también se hace parte de uno mismo, y sobre el que construimos una serie de imágenes y categorías que nos permiten ordenar el mundo y poder actuar en él con mayor seguridad (Pinxten 1998).

Respecto a la relación entre memoria y sujeto, Wieviorka (2001: 177-178) señala en primer lugar que en la memoria individual suelen no ser vistos referentes de la sociedad o el grupo al cual pertenezca el individuo, y se la considera como un atributo personal, como un elemento que define su personalidad y la unifica, pero que no reproduce la identidad, es decir, su continuidad en el tiempo. Sin embargo, Wieviorka sugiere como hipótesis que para la formación del sujeto se requiere el término de una negación, de un estigma, y como complemento o variante de esta condición,

"la decisión de rechazar la historia oficial (...). El momento en que la memoria se vuelve un propósito público es, por cierto, decisivo para la constitución del sujeto, quien, gracias a esta simple expresión y eventualmente al valor que le fue necesario para hablar, rompe el silencio y pone término a un olvido que conlleva fuertes dimensiones de indiferencia, de dominación, e incluso de alienación" (2001: 179).

La reivindicación de una historia que ya no es una versión oficial del poder permite la afirmación del sujeto, abriéndose a una nueva perspectiva en la que "la memoria que ve la luz llama a la libertad y a la intencionalidad del actor" (2001: 190).

Ahora bien, Wieviorka advierte de la paradoja en la memoria colectiva, en cuanto a su fragmentación como consecuencia de un exagerado sentimiento de pérdida y de las referencias a la destrucción de la sociedad. En este caso, las acciones se llevan a cabo

"en nombre de la justicia, de la denuncia de la barbarie sufrida, pero no alcanza[n] a promover reivindicaciones ligadas a una cultura activa y 
viva. Descansa[n] en una memoria que jala al actor hacia el pasado pero que no lo ayuda[n] a construirse proyectando su diferencia hacia el futuro" (Wieviorka 2001: 191).

En este sentido, el autor señala que en los escenarios contemporáneos, marcados por fenómenos que no se ciñen necesariamente a la correspondencia estrecha entre nación y sociedad, y en que lo colectivo no determina en su totalidad al individuo, la referencia a la memoria colectiva, para la diferenciación cultural -la identidad-, es un hecho importante sólo en la medida que cuestione la historia "desde el punto de vista de un actor que aspira a insertarse en un campo histórico" (2001: 191).

\section{Propuesta de análisis}

Mi propuesta de análisis gira fundamentalmente en torno a la invitación que plantea el propio Chihuailaf, de iniciar una conversación, de atender a su interpelación al pueblo chileno en Recado confidencial a los chilenos, y al mundo que evoca su imaginario poético. Se trata de una búsqueda a través del ejercicio de la memoria que realiza Chihuailaf, para encontrar, en definitiva, el espacio de la intersubjetividad que surge en la palabra como técnica de registro histórico y como inscripción. Descubrir (en cuanto acción de develar, des-cubrir) en la palabra dos mundos nombrados, un origen y un destinatario. Mapuche y chileno. Mundos cruzados por la palabra del poeta, donde el sentido deviene en ambos, y su resonancia también.

Con esto quiero expresar, a modo de hipótesis general y extensiva, que en la constitución de las subjetividades mapuche y chilena el elemento contrario (si lo pensamos como oposiciones) tiene su lugar, e incide en la configuración de identidades colectivas e individuales fundamentalmente desde la negación, y en menor grado desde la afirmación del otro. Sabemos que en el imaginario nacional chileno, al menos el mundo mapuche, e indígena en general, es reducido a un dato histórico, a las raíces de la nacionalidad, raíces que se hunden en el pasado. A un paso siempre de ser enterradas.

Pero en el mundo mapuche también encontramos una actitud defensiva, una resistencia a la imposición cultural que se autoidentifica en un pasado histórico-grupal. Una resistencia anterior al proceso reduccional, y una resistencia actual, que surge desde la ciudad -la waria-, manifestada de diversas maneras, ya sea en la producción cultural como en la acción política, y organizada en torno a la lucha contra la presencia de las empresas forestales en territorio mapuche.

Ahora bien, ¿cómo se plantea el autor ante la memoria? En Recado confidencial a los chilenos, en primer lugar se invita a un interlocutor imaginado -chileno- a establecer un diálogo también "imaginario", una conversación en confianza, de ahí su carácter de "confidencial".

Bajo la forma de una conversación, un diálogo (nvtram), el autor nos hace una invitación a escuchar, a conocer el mundo del cual proviene -un mundo particular y colectivo-, pero también su reflexión personal acerca de hechos que forman parte tanto de una historia oficial como de la memoria colectiva de su pueblo. Una memoria que no debe configurarse sólo sobre la restitución del pasado, sino hacia el futuro:

“(...) Desde el olvido entonces ha de ser levantada la conversación de los chilenos; desde el futuro de la memoria, me dicen, les digo a un grupo de estudiantes liceanas que han venido hasta mi casa.

¿Y qué es para usted el futuro?" (Chihuailaf en Recado Confidencial a los chilenos, p. 64).

La invitación de Chihuailaf es precisamente la toma de conocimiento de un saber ignorado por el destinatario de su mensaje y que supone ser a la vez su interlocutor: el pueblo chileno. Verdadera conversación con el pueblo chileno, con el ciudadano común, con "usted", que surge desde el escritorio, el lugar de la escritura (la habitación cerrada y solitaria, desde la soledad que impone este ejercicio).

" $Y$ es que usted y yo estamos hablando? Desde dos culturas, desde las diferentes concepciones de mundo que nos habitan, diversas y aún muy distantes: La cultura mapuche y la cultura chilena" (Chihuailaf en Recado confidencial a los chilenos, p. 28).

Esta conversación apunta a un reconocimiento mutuo a partir de puntos comunes, también deja en claro la distancia simbólica que separa a mapuche de chilenos, pero relevando lo que define como "vasos comunicantes que han influenciado a nuestros pueblos". 
De igual forma, deja en claro el hecho de que su discurso se basa en una experiencia de vida particular.

"Como me ha tocado vivir-al igual que todo ser humano- una historia particular dentro de la his-
"Y poesía es el canto de mis
Antepasados
el día de invierno que arde
y apaga
esta melancolía tan personal"

(Chihuailaf en De sueños azules y contrasueños, p. 61). toria general de mi Pueblo" (Chihuailaf en Recado confidencial a los chilenos, p. 23).

Así también su poesía como señala en los últimos versos del poema "La llave que nadie ha perdido"/Ini Rume Ñamvum Noel Chi Llafe":

"Ka vlkantun fey ñi vl tañi

pu Kuyfikeche

pukem antv mu vy lu ka chonglu

feyta chi kisu zwam weñagkvn"
Este plantearse la diversidad de ser mapuche me parece sugerente, en tanto habla desde sí mismo y desde la diferencia cultural. No es el pueblo mapuche en su conjunto que dice portar en sus palabras, ni se arroga su representación, sino, al contrario, es él quien se reclama a sí mismo como mapuche. Con esto quiero avanzar hacia la imagen de un sujeto que no sólo enuncia sino que también se enuncia, como poeta, como creador, pero también como sujeto reflexivo de su historia particular engarzada en la historia y cultura de su pueblo.

“(...) pertenezco al pueblo mapuche: soy una expresión de su diversidad. Y no hablo del pueblo en un sentido figurado, discursivo, porque es el Pueblo al que pertenece toda mi familia" (Chihuailaf en Recado confidencial a los chilenos, p. 25)

Respecto a la manera de concretar la invitación a establecer esta conversación, podríamos decir que en este texto encontramos dos zonas, una que es propiamente la de la memoria y otra que nos sitúa en problemáticas del presente. Porque digo que se trata propiamente de la memoria, porque a par-

\section{“(..)}

Por las noches oímos los cantos

cuentos y adivinanzas

a orillas del fogón

respirando el aroma del pan

horneado por mi abuela

mi madre o la tía María

mientras mi padre y mi abuelo

-Lonko de la comunidad-

observaban con atención y respeto

de la memoria de mi niñez.

$Y$ no de una sociedad idílica

(...)"

(Chihuailaf en De sueños azules y contrasueños, p. 25) tir de los recuerdos el autor pone en movimiento su relato, y su conversación. Aporta información valiosa, datos, imágenes de una cultura, que son entregadas desde su particular visión. Evoca el país azul, el país mapuche, para situarnos luego en el carácter del conflicto principal entre el Estado chileno y el pueblo mapuche. En este sentido, la Infancia constituye el núcleo de la identidad étnica, en cuanto ser mapuche, y en parte, surge desde el mundo reduccional.

"Durante los dos meses que trabajé en el presente texto, muchas veces recordé mis andanzas, junto a mi hermano Carlitos, en los bosques milenarios de la tierra de mis abuelos, en mi comunidad. Sabíamos adónde íbamos, adónde teníamos que llegar, pero las hojas del otoño o la nieve del invierno $y$, sobre todo, la enmarañada vegetación de la primavera, solían ocultar las débiles huellas que nosotros mismos habíamos dejado. Así muchas veces tuvimos que volver al punto de partida y rehacer el trayecto" (Chihuailaf en Recado confidencial a los chilenos, p. 9).

\section{O en "Sueño Azul"/ "Kallfv Pewma Mew":}

“(...)

Pun fey allkvtukeyiñ vl,epew

$\mathrm{ka}$ fill ramtun

inal kvtral mew

neyentu nefiyiñ ti nvmvn kvtral

kofke ñi kuku

ka ñi ñuke ka ñi palu María

welu ñi chaw egu tañi laku egu

-Logko lechi lof mew-

welu kvme az zuwam pukintu keygu

Pichikonagen chi zugu nvtram

kaken welu ayekan chi pu

kom zugu no (...)" 


\section{Oralidad, escritura y memoria}

Chihuailaf define su trabajo de creación como el de "oralitura" -y a sí mismo como un oralitorhaciendo referencia a la escritura "ejercida junto a la fuente de la oralidad de nuestros mayores" (ancestros, antepasados, memoria colectiva, tradición), pero también junto a sus amigos de la otra "orilla".

“(...) esta conversación con usted la realizo al lado de los pensamientos de mis antepasados, de mi gente; y de las reflexiones, las cartas y los libros de mis amigas y de mis amigos no indígenas (...) a ellos los he convocado a hablar en estas páginas.

A usted le convido a oírlas, a oírlos" (Chihuailaf en Recado confidencial a los chilenos, p. 39).

Ahora bien, el ejercicio de la escritura es realizado junto a la fuente de la oralidad "aún vigente", a "orillas del bosque de la memoria". Pero qué supone esta metáfora del bosque, ¿las tierras boscosas?, ¿la prodigalidad?, ¿o solamente el viaje hacia el interior de la naturaleza? ¿el paisaje interno de la cultura? Sugiero que un poco de todo, es una metáfora, pero en ella está contenida tradición, cultura, origen.

Frente a ella, y de ahí el título de este trabajo, ¿qué encontraríamos en el bosque de la escritura? Encontramos el Estado, la sociedad nacional, la cultura chilena, la ciudad y la modernidad.

Entre las dos orillas se sitúa el sujeto portador de una identidad étnica que cruza esos mundos, ingresando en ambos y rehaciendo su trayecto. Apropiándose en ese tránsito de valores que puedan ser considerados como positivos, proyectándose en esa apropiación desde una visión de mundo particular (Figura 2).

"La waria-ciudad-ahora un camino que hay que considerar para no ser derrotado definitivamente como cultura" (Chihuailaf en Recado confidencial a los chilenos, p. 28).

Por otra parte, también nos comenta que habiendo nacido y crecido en una comunidad (reducción) mapuche, aprendió el mapudungun de sus abuelos, pero también tuvo que hacer uso obligado del castellano, en su doble dimensión, es decir, en tanto imposición de la escuela (el Estado) y para evitar la discriminación por hablar su propia lengua. De esta manera, la escritura y los libros fueron en un principio objetos ajenos, del otro. El conocimiento que proporciona la palabra escrita hablaba de los "araucanos", de figuras de una historia oficial, no hablaban de los sujetos de la memoria, de la cotidianidad, de la experiencia de la identidad que se vive en la reducción.

En este sentido, la escritura se constituye como experiencia en la medida que define la identidad propia y la alteridad: "quien soy, quien es el otro". Pero es también el libro el que habla, es la fuente de la que mana la escritura, así como de la memoria fluye la oralidad.

El libro pertenecía al otro y hablaba de un otro, que suponía reflejar su identidad, pero que refleja sólo el imaginario de quien lo produce. De ahí que la escritura en este caso no puede ser considerada únicamente como apropiación de una téc-

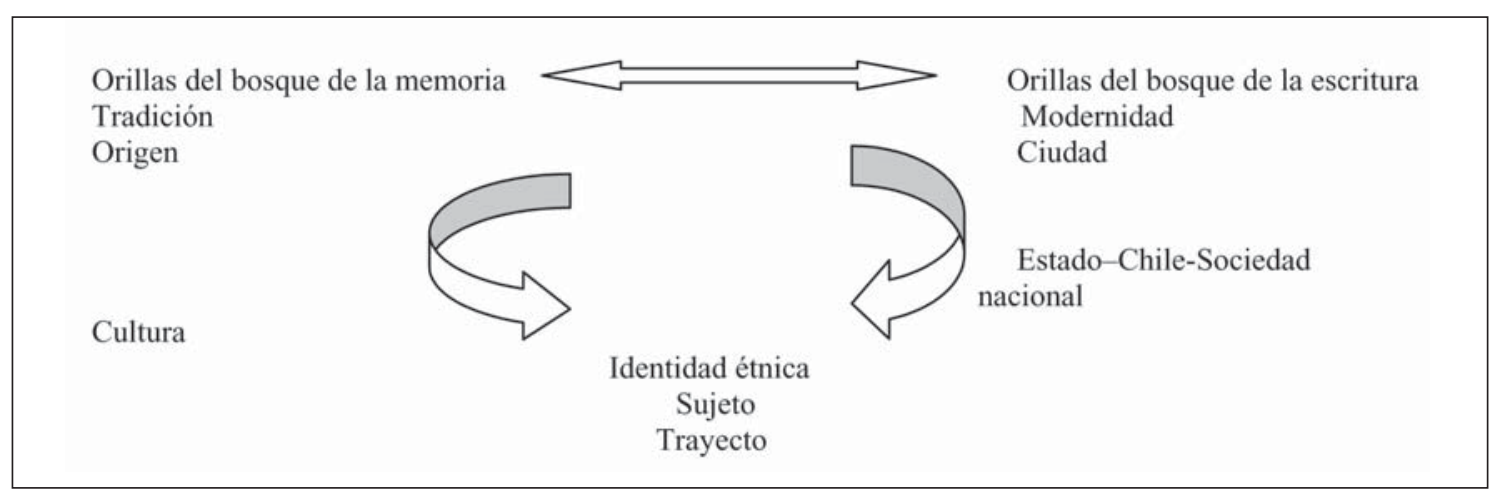

Figura 2. Esquema sugerido para graficar este tránsito y la posición del sujeto en aquel. 
nica ajena e impuesta, en cuanto constituye el enfrentamiento con la identidad definida desde el otro. Ese otro que "hace surgir a los araucanos". En este sentido, Chihuailaf a partir de la discusión sobre una identidad globalizada única desde la cual los pueblos indígenas serían vistos como fósiles, refiere al temor de las "sociedades globales" frente a la posibilidad de que los pueblos originarios sean capaces de "autopensarse". Entidades que desde esa perspectiva debieran ser conservadas en su condición "primitiva", porque no poseerían un dinamismo intrínseco, sino que obedecen a estímulos externos e ideas foráneas.

Por lo tanto, en Chihuailaf no sólo se constataría el registro de la memoria histórica a través de la escritura, sino también la apropiación individual de la escritura, en la medida que es este sujeto mapuche que lo experimenta, así como ha experimentado la otredad: el otro de los otros. La escritura en espejo, que devuelve el reflejo de la inscripción de una memoria hegemónica.
Así también, es posible visualizar la producción del libro, tornándose la identidad un acto performativo en la medida que con el desarrollo de su reflexión se va configurando más claramente en un proceso que debiera interpelar a su receptor, lector y destinatario de su recado. Resituando de esta manera la mirada acerca de la identidad mapuche respecto a su limitación a un espacio y tiempo predeterminado, y con ello a la diversidad que involucra ya no como una identidad preclara -independientemente de la existencia del pueblo mapuche como tal- única, estática. Abriéndose al presente, y sobre todo a un proyecto de futuro que prefigura no sólo un sujeto histórico, sino un sujeto comprometido en una acción colectiva pero que desde la conciencia de su historia individual fortalece y enriquece con su experiencia la cultura e historia de su pueblo.

Agradecimientos A Viviana Manríquez por darme la oportunidad de presentar este trabajo.

\section{REFERENCIAS CITADAS}

CARRASCO, I., 1995. Las voces étnicas en la poesía chilena actual. Revista Chilena de Literatura 47: 58-70.

2000. Poetas mapuches contemporáneos. Pentukun 10-11: $27-44$

FABIAN, J., 1983. Time and the other. How anthropology makes its object. Columbia University Press, Nueva York.

LE GOFF, J., 1991. El orden de la memoria. El tiempo como imaginario. Editorial Paidós, Barcelona.

PINXTEN, R., 1998. Identidad y conflicto: Personalidad, socialidad y culturalidad. En http:// www.cidob.es/ Catalan/Publicaciones.
TOURAINE, A., 1997. ¿Podremos vivir juntos? La discusión pendiente: El destino del hombre en la aldea global. Fondo de Cultura Económica, Buenos Aires.

WIEVIORKA, M., 2001. La diferencia. Plural Editores, La Paz.

\section{Fuentes documentales}

CHIHUAILAF, E., 1995. De Sueños azules y contrasueños, Editorial Universitaria, Santiago.

1999. Recado confidencial a los chilenos. Ediciones LOM, Santiago. 